\title{
Which is the Optimal Frozen Elephant Trunk? A Systematic Review and Meta-Analysis of Outcomes in 2161 Patients Undergoing Thoracic Aortic Aneurysm Surgery Using E-vita OPEN PLUS Hybrid Stent Graft versus Thoraflex ${ }^{\mathrm{TM}}$ Hybrid Prosthesis
}

\author{
Amer Harky', MSc, MRCS; Matthew Fok², MRCS; Mohamad Bashir ${ }^{3}$, MD, PhD, MRCS
}

DOI: $10.21470 / 1678-9741-2019-0220$

\begin{abstract}
Objective: To systematically review the rate of morbidity and mortality associated with the use of E-vita hybrid stent graft and ThoraflexTM in patients undergoing complex aortic surgery.

Methods: A comprehensive search was undertaken among the four major databases to identify published data about E-vita or Thoraflex ${ }^{\mathrm{TM}}$ in patients undergoing repair of thoracic aortic aneurysms.

Results: In total, 28 papers were included in the study, encompassing a total of 2,161 patients (1,919 E-vita and 242 Thoraflex ${ }^{\mathrm{TM}}$ ). Patients undergoing surgery with $\mathrm{E}$-vita or Thoraflex ${ }^{\mathrm{TM}}$ were of similar age and sex. The number of patients undergoing non-elective repair with Thoraflex ${ }^{\mathrm{TM}}$ was higher than with E-vita
\end{abstract}

(35.2\% vs. $28.7 \%$, respectively). Cardiopulmonary bypass time was associated with increasing mortality in E-vita patients, however a meta-analysis of proportions showed higher 30-day mortality, permanent neurological deficit, and one-year mortality for Thoraflex ${ }^{\mathrm{TM}}$ patients. Direct statistical comparisons between E-vita and Thoraflex ${ }^{\mathrm{TM}}$ was not possible due to heterogeneity of studies.

Conclusion: Although there are limited studies available, the available data suggests that mortality and morbidity are lower for the E-vita device in thoracic aortic aneurysm surgery than for Thoraflex ${ }^{\mathrm{TM}}$. Long-term data of comparative studies do not yet exist to assess viability of these procedures.

Keywords: Aortic Aneurysm, Thoracic. Tocopherols. Cardiopulmonary Bypass. Stents. Morbidity.

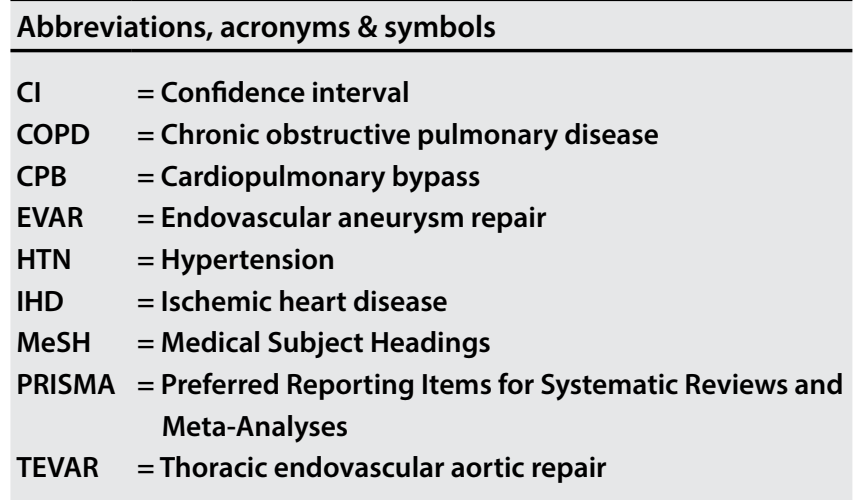

'Department of Cardiothoracic Surgery, Liverpool Heart and Chest Hospital, Liverpool, United Kingdom.

2Department of Vascular Surgery, Royal Liverpool Hospital, Liverpool, United Kingdom.

${ }^{3}$ Vascular Surgery Department, Royal Blackburn Teaching Hospital, Haslingden Rd, Blackburn, United Kingdom.

\section{INTRODUCTION}

The introduction of the elephant trunk technique by Borst et al. in 1983 facilitated the arch and distal aortic aneurysm repair in two stages ${ }^{[1]}$. The first stage was entailed ascending and aortic arch replacement through median sternotomy, while at the second stage, a free-floating conventional elephant trunk resultant of an extension of the arch prosthesis was left behind in the proximal descending aorta ${ }^{[2,3]}$.

In 1996, the development of a new elephant trunk prosthesis facilitated the treatment of aortic arch and proximal descending pathologies in a single operation. This was aimed at minimizing complications associated with the two-staged conventional elephant trunk. This new elephant trunk was known as "the

Correspondence Address:

Mohamad Bashir

(iD) https://orcid.org/0000-0002-1089-3629

Department of Aortovascular Surgery, Manchester Royal Infirmary

Oxford Road, M13 9WL, Manchester, United Kingdom

E-mail:drmbashir@mail.com 
frozen elephant technique". The new device promoted the hybrid approach in which the endovascular component can be performed either simultaneously or in stages. The "hybrid" vascular graft made up of a conventional tube graft with an endovascular stented graft at the distal end was used to achieve a blood-tight seal in the descending aorta ${ }^{[4-6]}$. This permitted dual interventions, the aortic arch and the proximal descending pathologies, in a single operation. The latter was aimed at minimizing complications and reducing the high mortality associated with the classical elephant technique ${ }^{[7,8]}$.

The advent of this new device technology in prosthesis design from both commercially available devices, the JOTECE-vita (JOTEC GmbH, Hechingen, Germany) and the Thoraflex ${ }^{\text {TM }}$ (VASCUTEK, Terumo, Inchinnan, Scotland, United Kingdom) prostheses, necessitated an appraisal of published outcomes. This systematic review and meta-analysis aims to evaluate the latest evidence regarding outcomes from the aforementioned devices.

\section{METHODS}

\section{Literature Search Strategy}

Electronic database searches were performed with MEDLINE, Google Scholar, Ovid, and Scopus from inception to December 2017. Limits were placed on manuscripts written in the English language only. Search terms used included Thoraflex, Evita, frozen elephant trunk, FET, aortic hybrid procedures, and thoracic hybrid procedures.

To achieve maximum sensitivity, all search terms were combined with Boolean operators and searched as both keywords and Medical Subject Headings (MeSH) terms. Following exclusion of articles based on title or abstract, full text articles selected had reference lists searched for any potential further articles to be included in this review.

\section{Selection Criteria}

Studies in which patient cohorts underwent thoracic aortic surgery with frozen elephant trunk, with either E-vita device or Thoraflex ${ }^{\mathrm{T} M}$, in any type of pathology, including type A chronic dissection with residual disease, chronic type B dissection, and aneurysmal disease, were included. Studies were excluded if they included a paediatric population, case reports, or small case series, reviews, or editorials. When institutions published duplicate studies with accumulating numbers of patients or increased lengths of follow-up, only the most complete reports were included for quantitative assessment at each time interval.

\section{Data Extraction and Critical Appraisal}

Data was extracted by two independent reviewers, and if necessary, a third was consulted to resolve disagreements. The information was extracted from studies that had met the inclusion criteria: baseline demographics and preoperative characteristics, operative urgency, extent of disease, cardiopulmonary bypass (CPB) time, cross-clamp time, type of brain protection strategy used, length of stay, postoperative stroke/paraplegia, and inhospital mortality and mortality at one year, five years, and 10 years. The quality of evidence from each study was assessed using the Moose system.

\section{Statistical Analysis}

Standard descriptive statistics (reported as means with 95\% confidence intervals $[\mathrm{Cl}]$ ) were used to summarize demographic and baseline data of the recruited patients from all eligible studies. Meta-analyses of outcomes when reported were performed on the reported incidence of 30-day mortality, inhospital stroke, and one-year mortality. Relative risk was used as summary. Heterogeneity among studies was estimated with $X^{2}$ tests, which was reported as the 12 statistic to estimate the percentage of total variation across studies, due to heterogeneity rather than chance.

Dependant on the heterogeneity determined, a fixed or a random effect model was used. All statistical analyses were conducted with the Review Manager software (Cochrane Collaboration, Software Update, Oxford, United Kingdom), version 5.1.2.

\section{RESULTS}

\section{Baseline Demographics}

In total, 28 papers were included in the study ${ }^{[9-37]}$, all were published after 2008, and they comprised a total of 2,161 patients (1,919 E-vita and 242 Thoraflex ${ }^{\mathrm{TM}}$ ) (Figure 1). Patients undergoing surgery with E-vita or Thoraflex ${ }^{\mathrm{TM}}$ were of similar age and sex (mean age 61.0 vs. 61.3, respectively; male percentage 70\%) and the number of patients undergoing emergency repair with Thoraflex ${ }^{\top M}$ was higher than with E-vita (35.2\% vs. 28.7\%, respectively). Other baseline characteristics including diabetes, hypertension, ischaemic heart disease, previous stroke, previous cardiac surgery, renal disease, or Marfan syndrome were recorded poorly and are available in Table 1. Operative urgency (elective, emergency, mixed), aneurysm pathology (aneurysm, dissection, mixed), and extent of the disease pathology (ascending arch, descending arch, and descending) are available in Table 2.

Age is represented in Figure 2 by a bubble chart showing the relationship between 30 -day mortality and average age in studies with E-vita and Thoraflex ${ }^{\mathrm{TM}}$. CPB is represented by a bubble chart that shows that increasing CPB is associated with an increase in 30-day mortality, particularly in E-vita studies (Figure 3).

\section{Thirty-day Mortality}

Thirty-day mortality is represented by a proportional metaanalysis plot for E-vita and Thoraflex ${ }^{\mathrm{TM}}$ studies (Figures 4 and 5 , respectively). Data was available in 22 papers for E-vita and four papers for Thoraflex ${ }^{\text {TM }}$.

Proportional meta-analysis revealed a higher 30-day mortality with Thoraflex ${ }^{\top \mathrm{M}}$ than with E-vita: pooled proportion, fixed effect (3.295 95\% Cl, 2.546 to 4.189), I2 56.97\% (95\% Cl, 30.78 to 73.25 ) with E-vita vs. pooled proportion, fixed effect (6.988 95\% Cl, 3.891 to 11.412$), 1261.78 \%(95 \% \mathrm{Cl}, 0.00$ to 85.61$)$ with Thoraflex ${ }^{\mathrm{TM}}$. Funnel plots for both Thoraflex ${ }^{\mathrm{TM}}$ and E-vita proportional metaanalyses are shown in Figures $6 \mathrm{~A}$ and $6 \mathrm{~B}$, respectively. 


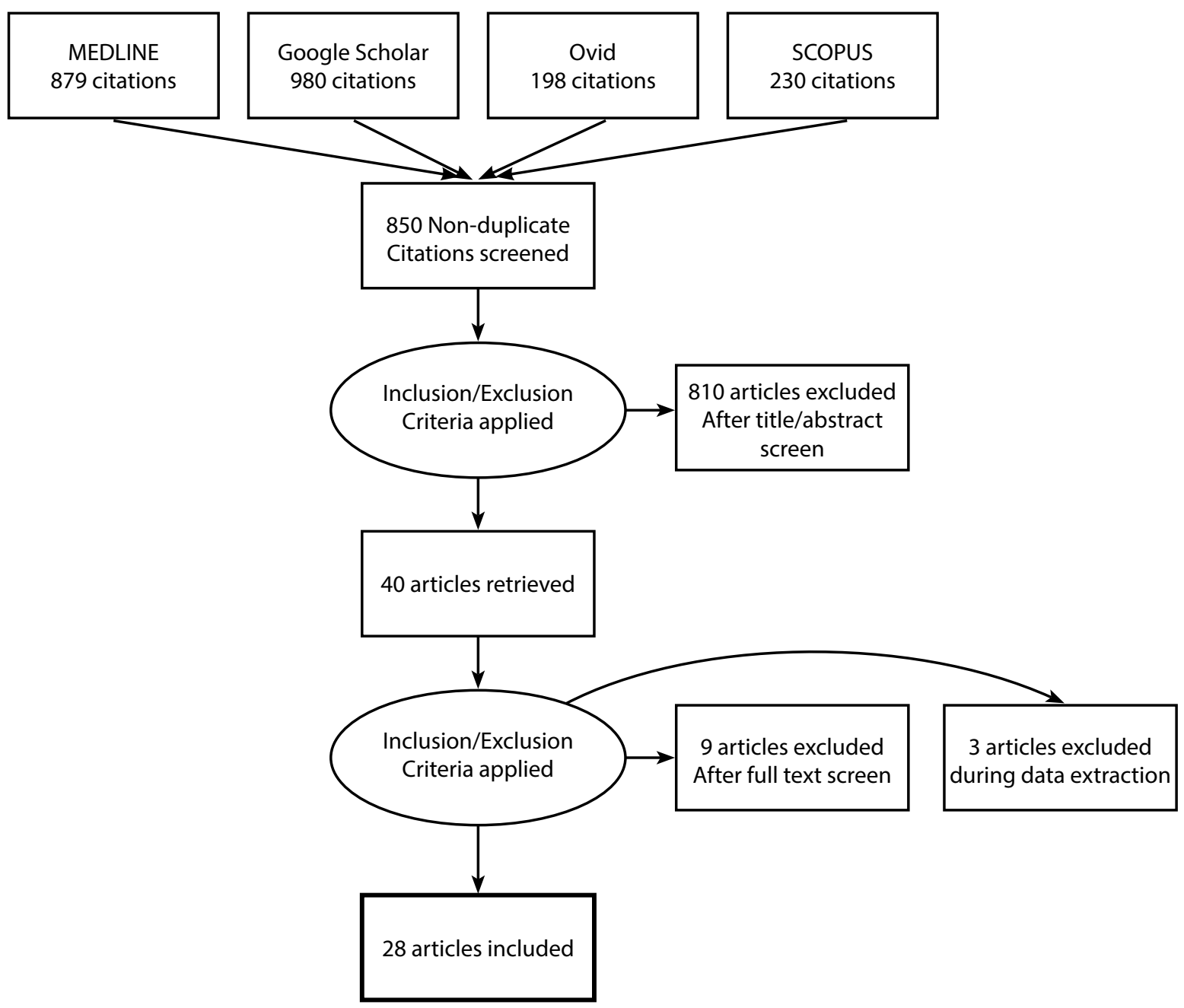

Fig. 1 - Preferred Reporting Items for Systematic Reviews and Meta-Analyses (PRISMA) chart.

\section{In-hospital Stroke}

In-hospital stroke is represented for both E-vita and Thoraflex ${ }^{\mathrm{TM}}$ by a forest plot proportional meta-analysis (Figures 7 and 8). Data was available in 22 papers for E-vita and four papers for Thoraflex ${ }^{\top M}$. Proportional meta-analysis revealed a higher in-hospital stroke rate with Thoraflex ${ }^{\top M}$ than with E-vita: pooled proportion, fixed effect (5.417 95\% Cl, 4.426 to 6.554), 12 74.09\% (95\% Cl, 60.24 to 83.12) with E-vita vs. pooled proportion, fixed effect (13.737 95\% Cl, 9.149 to 19.517$), 1242.74 \%(95 \% \mathrm{Cl}$, 0.00 to 80.78 ) with Thoraflex ${ }^{\text {TM }}$. Funnel plots for both E-vita and Thoraflex ${ }^{\mathrm{TM}}$ proportional meta-analyses are shown in Figures $9 \mathrm{~A}$ and $9 \mathrm{~B}$, respectively.

\section{One-year Mortality}

One-year mortality is represented for both E-vita and Thoraflex ${ }^{\mathrm{TM}}$ by a forest plot proportional meta-analysis (Figures 10 and 11). Data was available in 17 papers for E-vita and three studies for Thoraflex ${ }^{\mathrm{TM}}$. One-year mortality was higher with Thoraflex ${ }^{\mathrm{TM}}$ than with E-vita: pooled proportion, fixed effect (17.041 95\% Cl, 14.856 to 19.405$), 1294.42 \%(95 \%$ Cl, 92.24 to 95.98$)$ with E-vita vs. pooled proportion, fixed effect (21.25 95\% Cl, 15.392 to 28.127), I2 72.28\% (95\% Cl, 6.39 to 91.79) with Thoraflex ${ }^{\mathrm{TM}}$. Funnel plots for both E-vita and Thoraflex ${ }^{\mathrm{TM}}$ proportional meta-analyses are shown in Figures 12A and 12B, respectively.

\section{DISCUSSION}

The conventional elephant trunk technique requires a twostage operation. Each stage is associated with its own mortality and morbidity risks. The first-stage mortality rate ranges from $0 \%$ to $32.1 \%{ }^{[35,36]}$, and second stage ranges from $0 \%$ to $33.3 \%{ }^{[35,36]}$. However, the frozen elephant technique, which promoted a single stage aortic repair, represented a mortality ranging from $0 \%$ to $12.8 \%{ }^{[37]}$. In two studies that compared conventional and frozen elephant trunk techniques, the rate of in-hospital deaths was similar among both techniques; the mean in-hospital mortality for elephant trunk technique was $21.6 \%$ and $13.9 \% \%^{[22,26]}$ and for frozen elephant trunk technique it was $8.7 \%{ }^{[25]}$ and 


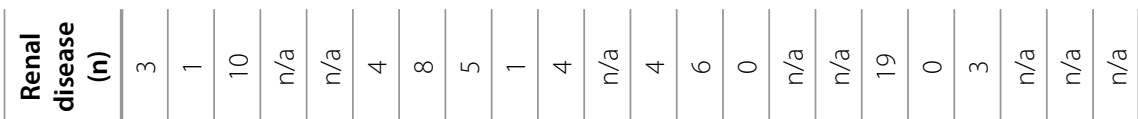

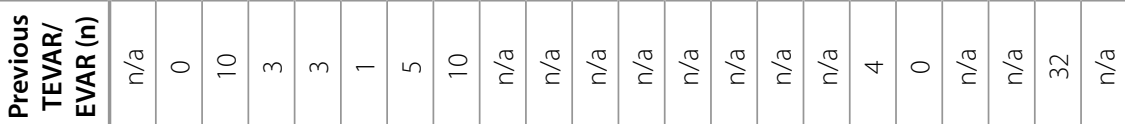

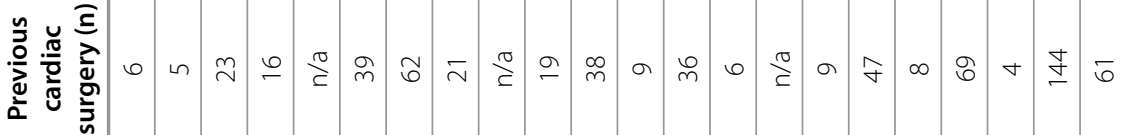

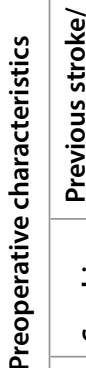

呈玉 n 总 $\bar{c} n$ n

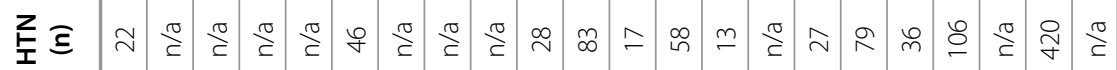

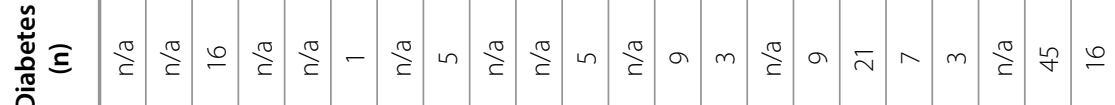

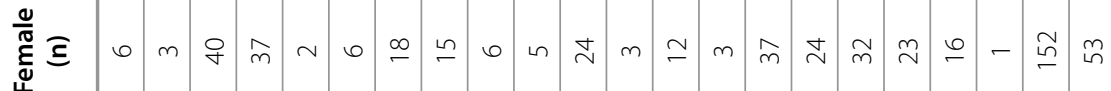

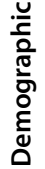

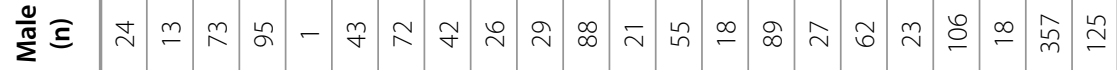

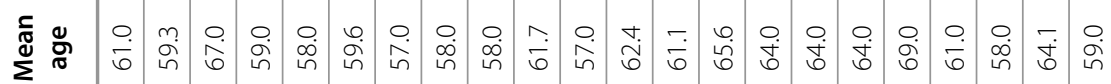

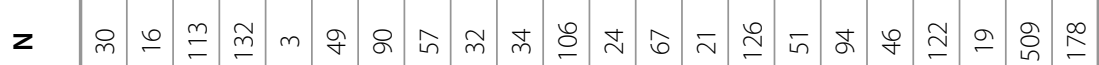

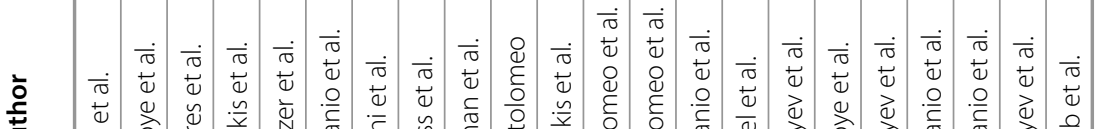

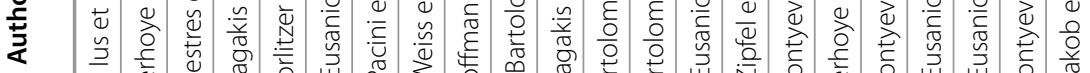

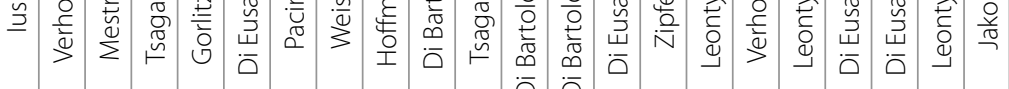

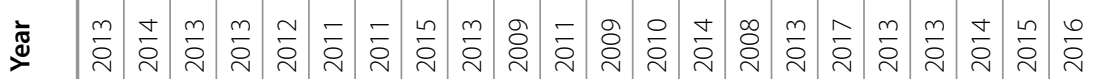

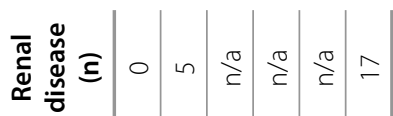

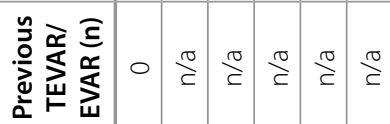

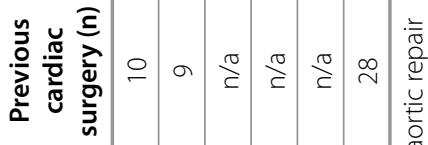

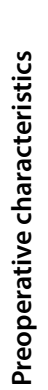

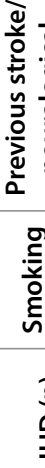

高

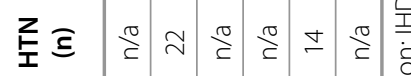

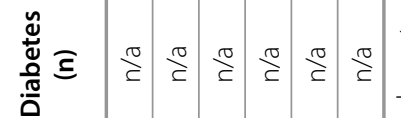

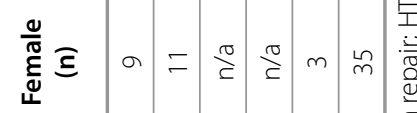

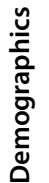

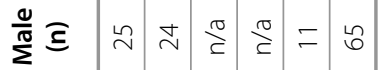
趈

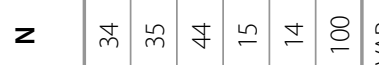

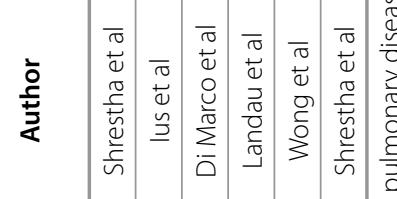
离

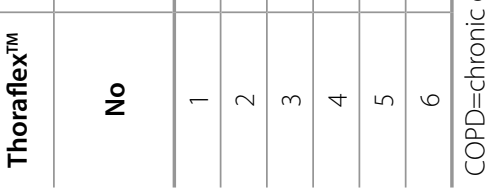


Table 2. Disease characteristics.

\begin{tabular}{l|c|c|c}
\hline \multicolumn{2}{c|}{} & E-vita & Thoraflex $^{\text {TM }}$ \\
\hline \multirow{3}{*}{ Operative urgency* } & Elective & $718(71.2 \%)$ & $92(64.8 \%)$ \\
\hline \multirow{3}{*}{ Pathology* } & Non-elective & $290(28.7 \%)$ & $50(35.2 \%)$ \\
\cline { 2 - 4 } & Aneurysm & 578 & 57 \\
\cline { 2 - 4 } & Dissection & 1239 & 112 \\
\cline { 2 - 4 } Extent of aneurysm* & Mixed & 92 & 0 \\
\cline { 2 - 4 } & Ascending & 427 & 42 \\
\cline { 2 - 4 } & Arch & 109 & 11 \\
\hline
\end{tabular}

${ }^{*}$ Data not available in all studies.

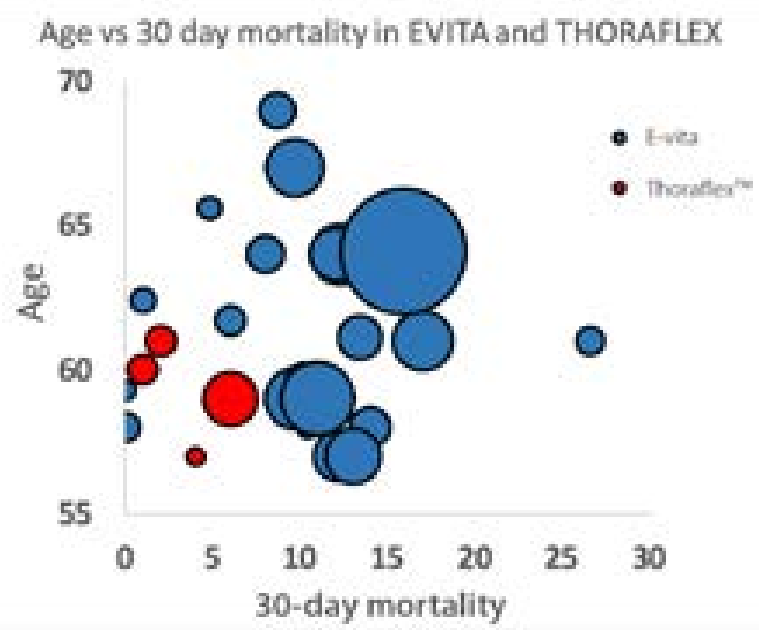

Fig. 2 - Bubble chart displaying the average age of patients in each study against 30-day mortality. E-vita and ThoraflexTM studies are represented by the colours blue and red, respectively (the bubble's size is weighted with patient years of follow-up of each study, studies from the same centre that may represent similar or overlapping patients were removed to avoid duplication).

4.8\% ${ }^{[26]}(P \geq 0.100)^{[22,26]}$. However, it becomes crucial to delineate the type of device used, the indications, and pathology. The advent of VASCUTEK Thoraflex ${ }^{\text {TM }}$ Hybrid prosthesis meant that both home and commercially available devices had to be lined up for comparison based on outcomes and false lumen thrombosis. In this review, we looked at every study that utilized frozen elephant trunk and as intended we exposed the device used and compared the outcomes published.

Tian et al. ${ }^{[37]}$ in a previous meta-analysis focused on the safety and efficacy of the frozen elephant trunk technique. They deduced in their analysis, which included 17 observational studies, a pooled mortality of $8.3 \%$, stroke rate of $4.9 \%$, and spinal

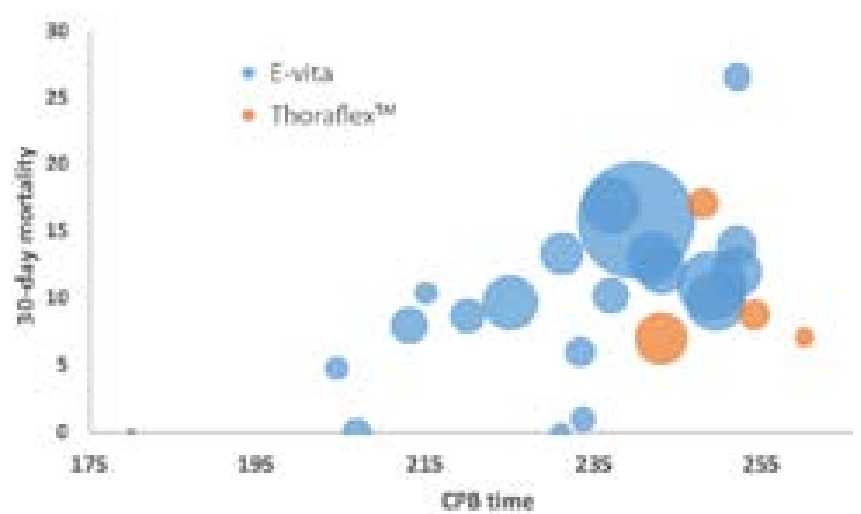

Fig. 3 - Bubble chart displaying the average cardiopulmonary bypass (CPB) time of patients in each study against 30-day mortality. E-vita and ThoraflexTM studies are represented by the colours blue and orange, respectively (the bubble's size is weighted with patient years of follow-up of each study, studies from the same centre that may represent similar or overlapping patients were removed to avoid duplication).

cord injuries rate of $5.1 \%$. Amongst their studies, only five studies reported the five-year survival to be between 63\% and 88\%.

They also reported a strong linear correlation of length of time for CPB, myocardial ischemia, and circulatory arrest with perioperative mortality. When we looked into this microscopically, CPB time was associated with increasing mortality in the E-vita group, however meta-analysis of proportions showed a higher 30-day mortality and one-year mortality for Thoraflex ${ }^{\mathrm{TM}}$. This paradox surely could be explained by the fact that the number of patients undergoing emergency repair with Thoraflex ${ }^{\mathrm{TM}}$ was higher than those with E-vita. Alternatively, another thought for this paradox is based on a rather hard to quantify concept 


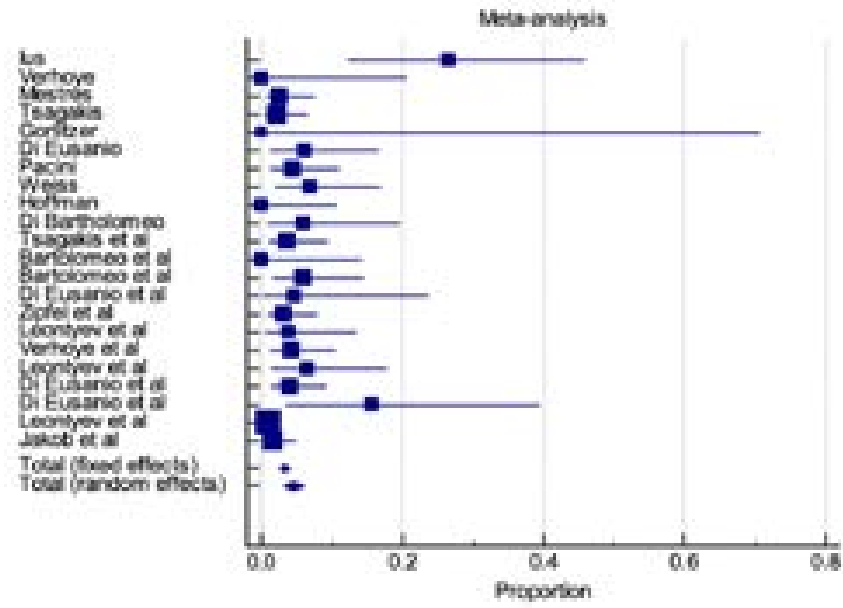

Fig. 4 - Forest plot displaying proportional meta-analysis plot for 30-day mortality with E-vita. Fixed effect (3.295 95\% Cl, 2.546 to 4.189), $1256.97 \%$ (95\% Cl, 30.78 to 73.25). Cl=confidence interval.

A

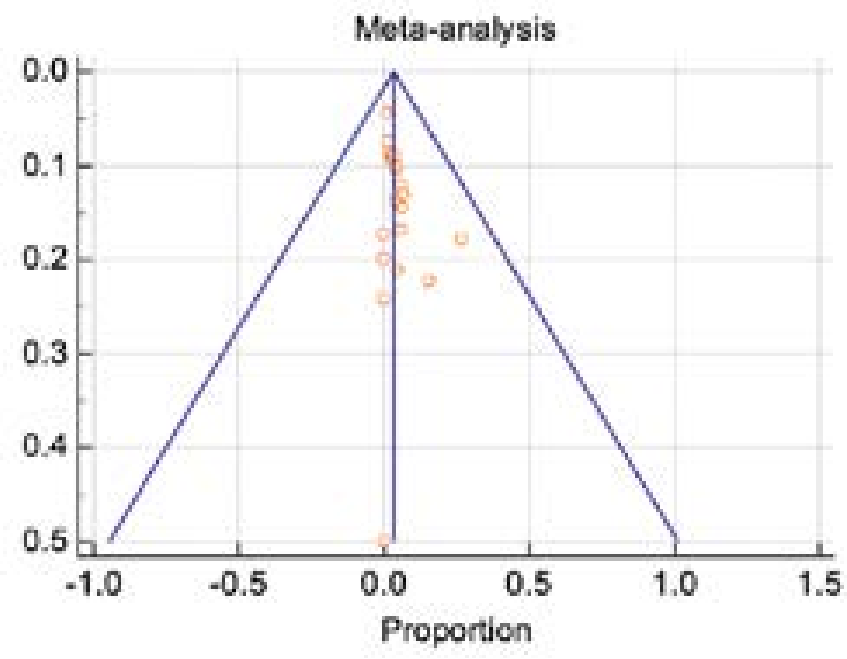

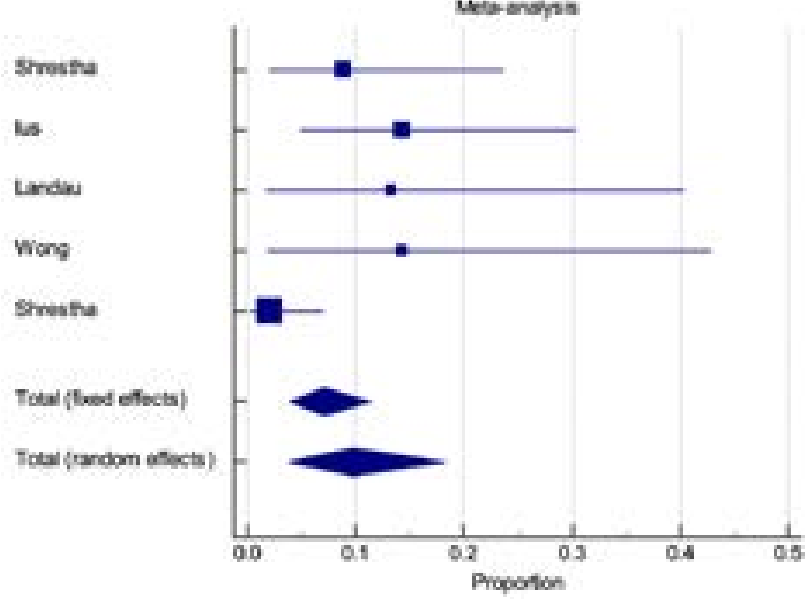

Fig. 5 - Forest plot displaying proportional meta-analysis plot for 30-day mortality with ThoraflexTM. Fixed effect (6.988 95\% Cl, 3.891 to 11.412$), 1261.78 \%(95 \% \mathrm{Cl}, 0.00$ to 85.61$)$. Cl=confidence interval.

\section{B}

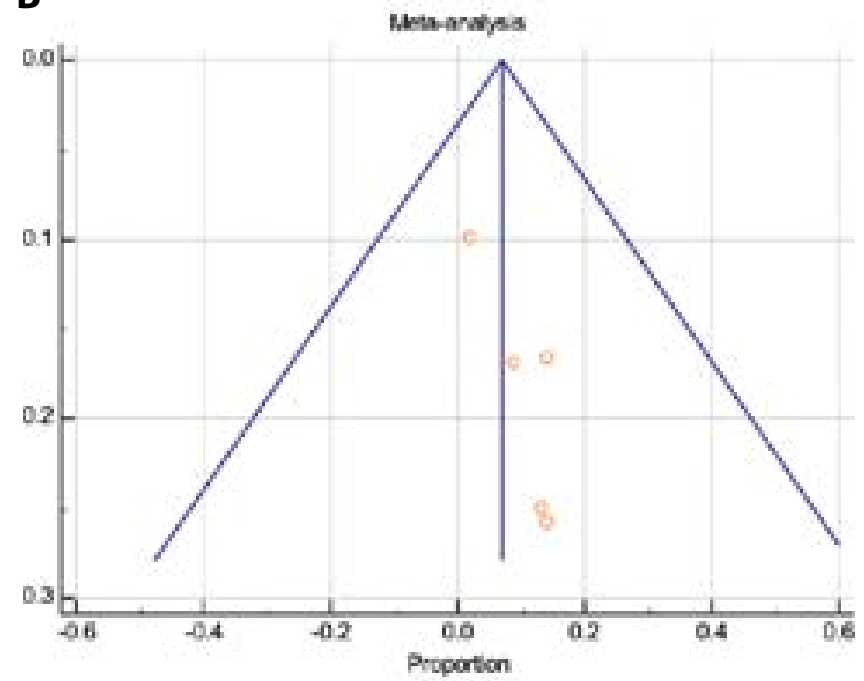

Fig. 6 A and B - Publication bias assessment via funnel plots for 30-day mortality with E-vita and ThoraflexTM, respectively.

regarding the understanding and application of device technology used in multiple aortic extent operations. The fact that E-vita was launched and used previously to Thoraflex ${ }^{\mathrm{TM}}$ allowed us as surgeons to appreciate the concept of frozen elephant trunk device and ability to interpret and make decisions on procedural extent and surgical applications.

In a meta-analysis done by a group from Taiwan ${ }^{[37]}$ on the efficacy and safety of the frozen elephant technique in the setting of acute type A aortic dissection, they reported an overall in-hospital mortality rate of $8 \%$. The authors indicated clearly in their analysis that based on their findings the frozen elephant technique does not bring unacceptable mortality or morbidity risks for treating acute type A aortic dissection aggressively with frozen elephant trunk. Hence, if we dissect this further, we note that Thoraflex ${ }^{\mathrm{TM}}$ Hybrid prosthesis was clearly utilized more frequently in emergency settings across the studies we pooled and that it clearly represents a focal point - that this device despite its wide use in emergency setting had rather less efficacious and safe proviso. Compounding this further, the permanent neurological deficit that we found was higher amongst the Thoraflex ${ }^{\mathrm{TM}}$ group. Surely and again, this is true because the device was being used rather more frequently in the emergency setting. This further raises another intriguing point regarding the aggressiveness and extent of the aortic segment 


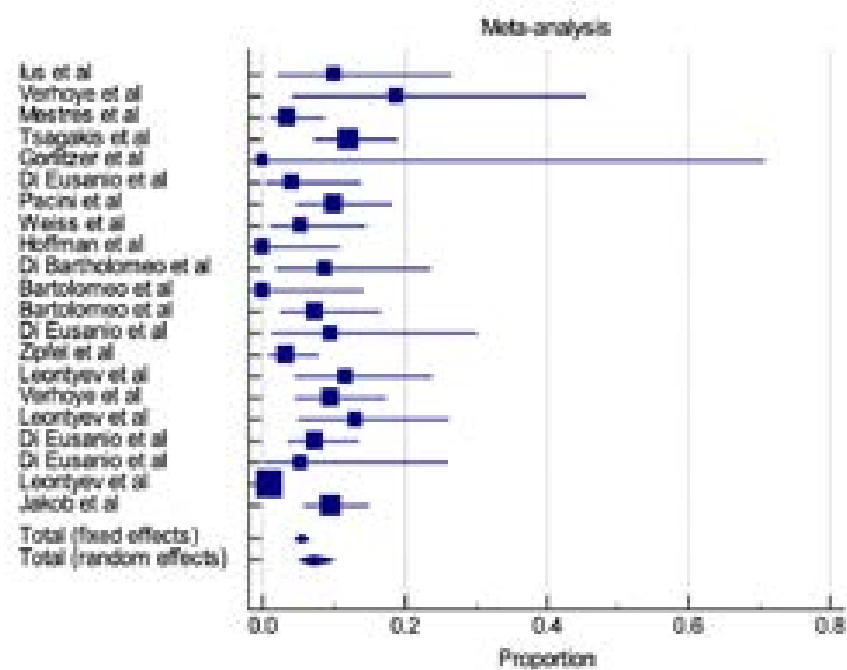

Fig. 7 - Forest plot displaying proportional meta-analysis plot for in-hospital stroke with E-vita. Fixed effect $(5.41795 \% \mathrm{Cl}, 4.426$ to 6.554), $1274.09 \%$ (95\% Cl, 60.24 to 83.12). Cl=confidence interval.

\section{A}

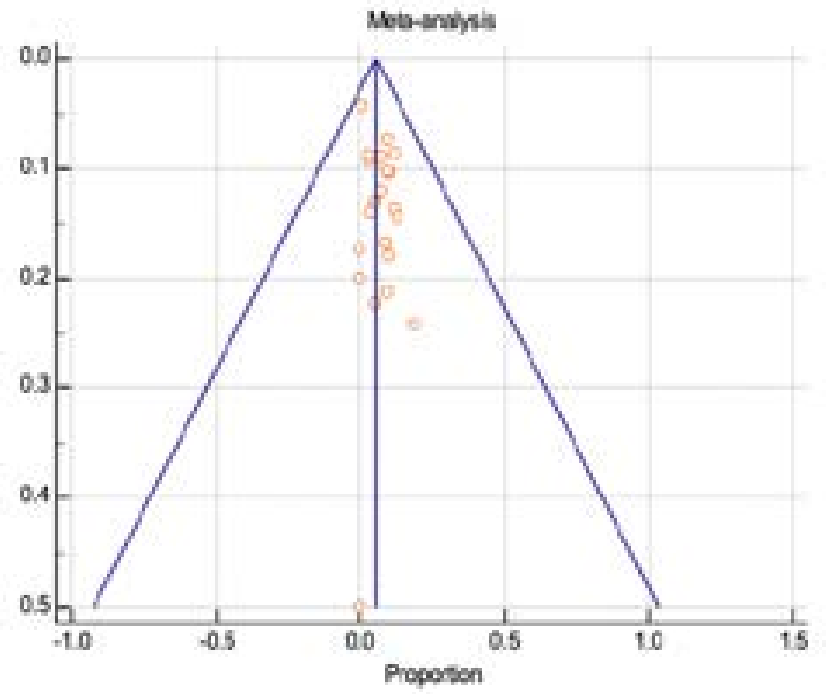

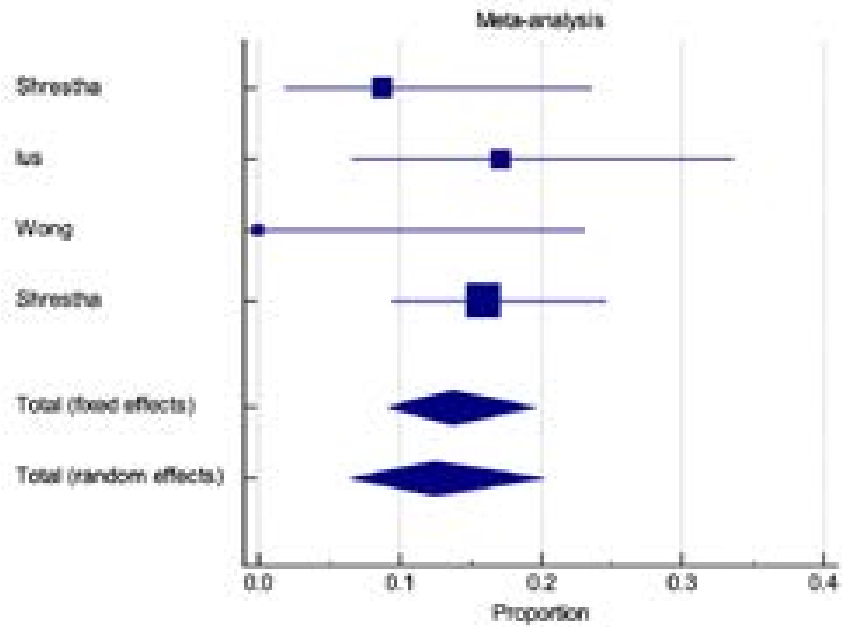

Fig. 8 - Forest plot displaying proportional meta-analysis plot for in-hospital stroke with ThoraflexTM. Fixed effect $(13.73795 \% \mathrm{Cl}$, 9.149 to 19.517 ), $1242.74 \%$ ( $95 \% \mathrm{Cl}, 0.00$ to 80.78$)$. Cl=confidence interval.

B

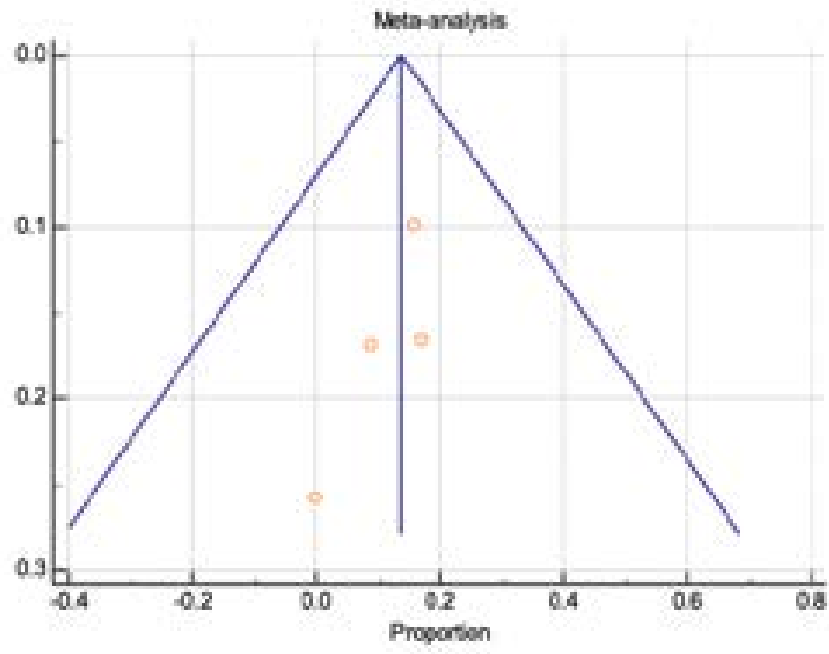

Fig. 9 A and B - Publication bias assessment via funnel plots for in-hospital stroke with E-vita and ThoraflexTM, respectively.

replaced during a given emergency setting. One could argue this based on the fact that results could be potentially skewed owing to publication bias, however, as shown in Figure 6A, the sensitivity and publication bias analyses for the E-vita device were rather indicative that the findings were robust; none of the study overly influenced the findings and there was no publication bias. However, for the Thoraflex ${ }^{\mathrm{TM}}$ group, this was equivocal (Figure $6 \mathrm{~B})$. We think this was potentially due to the scarcity in outcome reporting on studies utilizing Thoraflex ${ }^{\top M}$ device. This was seen again in figures depicting in-hospital stroke between the two devices. Surely, we can deduct from this that the evidence of the robustness of Thoraflex ${ }^{\mathrm{TM}}$ use and the judgement regarding its supremacy over the former E-vita device are questionable and opened to many interpretations.

In their meta-analysis review on hybrid arch techniques to provide a safe alternative to open repair, a group from Athens ${ }^{[38]}$ reported that acceptable short- and mid-term results remain debatable, with immediate need for prospective trials to compare open conventional techniques with the hybrid methods using hybrid device prosthesis with or without endovascular methods.

\section{CONCLUSION}

The implementation of new surgical techniques offers chances but carries risks. The frozen elephant trunk technique 


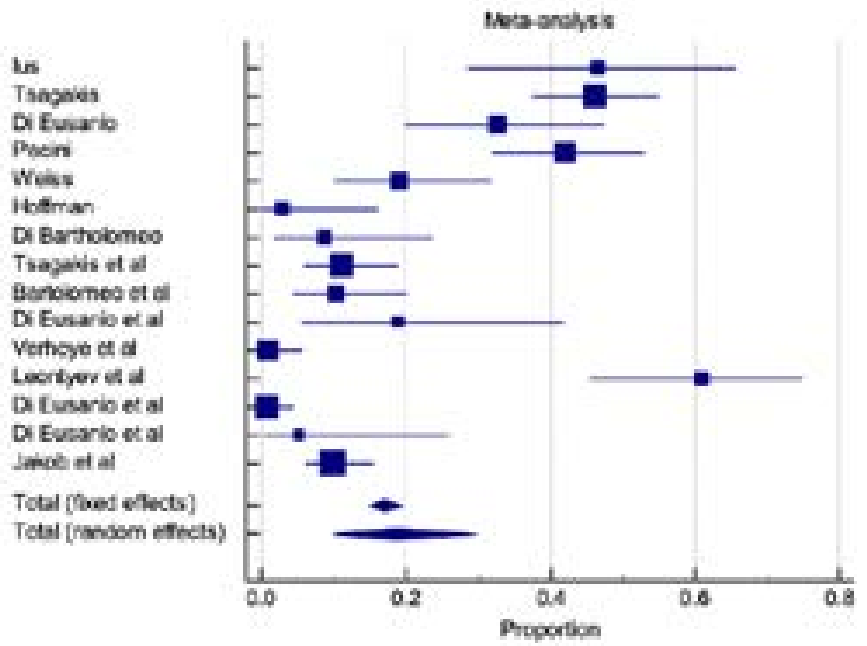

Fig. 10 - Forest plot displaying proportional meta-analysis plot for one-year mortality with E-vita. Fixed effect (17.041 95\% Cl, 14.856 to 19.405), 12 94.42\% (95\% Cl, 92.24 to 95.98). Cl=confidence interval.

A

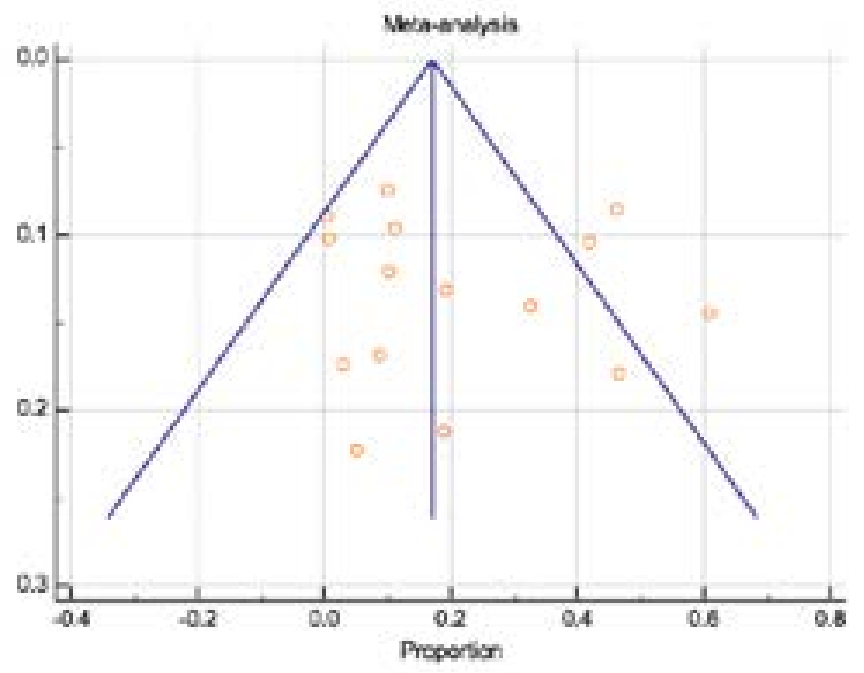

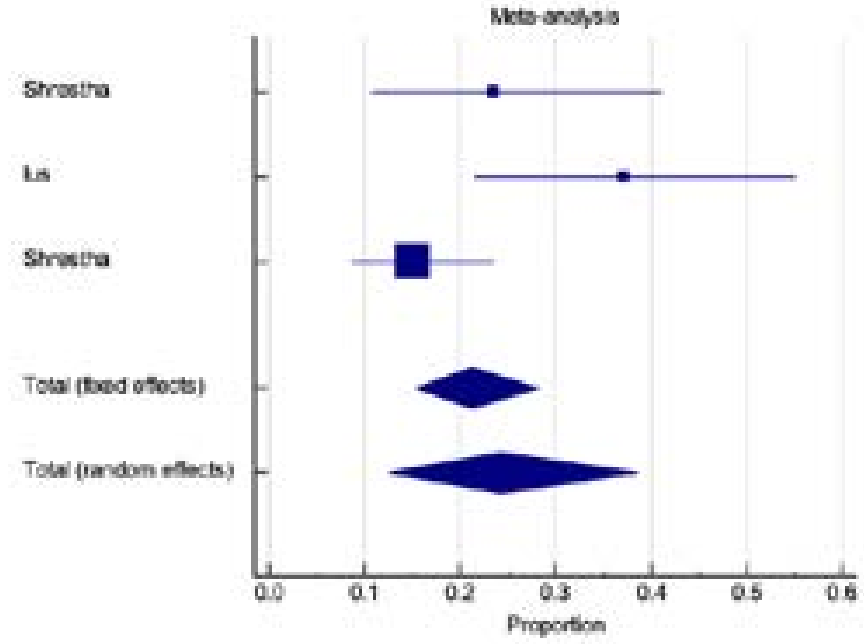

Fig. 11 - Forest plot displaying proportional meta-analysis plot for one-year mortality with ThoraflexTM. Fixed effect $(21.2595 \% \mathrm{Cl}$, 15.392 to 28.127 ), $1272.28 \%$ (95\% Cl, 6.39 to 91.79). Cl=confidence interval

\section{B}

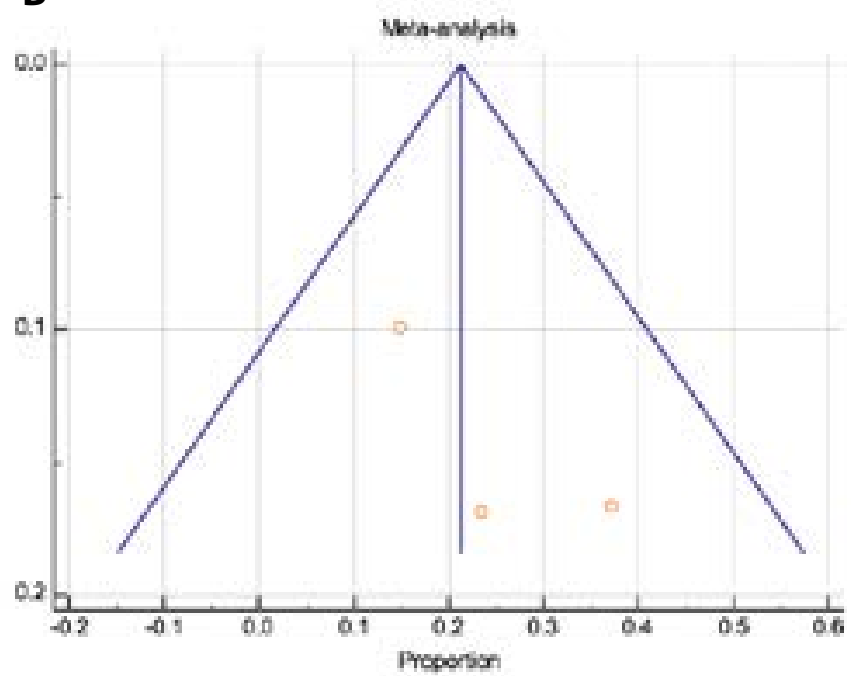

Fig. 12 A and B - Publication bias assessment via funnel plots for one-year mortality with E-vita and ThoraflexTM, respectively.

has increasingly been used to treat complex aortic pathologies of the aortic arch and the descending aorta, however, it's prudent to elicit as this review demonstrated that there is still an ongoing discussion regarding the optimal frozen elephant trunk use and its indications. Although there are limited studies available, the available data suggests that mortality and morbidity were lower for the E-vita device on surgeries in thoracic aortic aneurysm surgery.

\section{Limitations}

There are several limitations to our analysis that should be considered when interpreting the results. The number of comparative studies included in our analysis was too small to perform a comparison of the frozen elephant technique with other techniques to treat type A aortic arch dissection. Direct statistical comparisons between E-vita and Thoraflex ${ }^{\text {TM }}$ was not possible due to heterogeneity of studies. Most of the included studies were retrospective in design and differences in surgical parameters and patient baseline characteristics may partially explain the heterogeneity seen across the studies and possibly affect our results. There was little information in the included studies regarding long-term survival, indicating the need for well-designed long-term studies to investigate this question. 


\section{No financial support. \\ No conflict of interest.}

Meeting Presentation: This abstract has been presented as a poster (presentation on demand) at AATS aortic symposium, April 26-27, 2018, New York, United States of America.

\section{Authors' roles \& responsibilities}

AH Substantial contributions to the conception or design of the work; or the acquisition, analysis, or interpretation of data for the work; drafting the work or revising it critically for important intellectual content; final approval of the version to be published

MF Substantial contributions to the conception or design of the work; or the acquisition, analysis, or interpretation of data for the work; drafting the work or revising it critically for important intellectual content; final approval of the version to be published

MB Substantial contributions to the conception or design of the work; or the acquisition, analysis, or interpretation of data for the work; drafting the work or revising it critically for important intellectual content; final approval of the version to be published

\section{REFERENCES}

1. Borst H, Walterbusch G, Schaps D. Extensive aortic replacement using "elephant trunk" prosthesis. Thorac Cardiovasc Surg. 1983;31(1):37-40. doi:10.1055/s-2007-1020290.

2. LeMaire SA, Carter SA, Coselli JS. The elephant trunk technique for staged repair of complex aneurysms of the entire thoracic aorta. Ann Thorac Surg. 2006;81(5):1561-9; discussion 1569. doi:10.1016/j. athoracsur.2005.11.038.

3. Karck M, Kamiya H. Progress of the treatment for extended aortic aneurysms; is the frozen elephant trunk technique the next standard in the treatment of complex aortic disease including the arch? Eur J Cardiothorac Surg. 2008;33(6):1007-13. doi:10.1016/j.ejcts.2008.02.030.

4. Harris R, Croce B, Tian DH. Hybrid aortic arch surgery. Ann Cardiothorac Surg. 2013;2(5):680.

5. Oderich GS, Power AH. Hybrid repair of aortic arch aneurysms. In: Ascher E, editor. Haimovici's Vascular Surgery. 6th. ed. West Sussex (UK): Willey-Blackwell; 2012. p. 486-503.

6. Bashir M, Harky A, Bilal H. Is there a prospect for hybrid aortic arch surgery? Gen Thorac Cardiovasc Surg. 2019;67(1):132-6. doi:10.1007/ s11748-018-0940-z.

7. Azizzadeh A, Estrera AL, Porat EE, Madsen KR, Safi HJ. The hybrid elephant trunk procedure: a single-stage repair of an ascending, arch, and descending thoracic aortic aneurysm. J Vasc Surg. 2006;44(2):404-7. doi:10.1016/j.jvs.2006.04.041.

8. Younes HK, Davies MG, Bismuth J, Naoum JJ, Peden EK, Reardon MJ, et al. Hybrid thoracic endovascular aortic repair: pushing the envelope. J Vasc Surg. 2010;51(1):259-66. doi:10.1016/j.jvs.2009.09.043.
9. Ius F, Fleissner F, Pichlmaier M, Karck M, Martens A, Haverich A, et al. Total aortic arch replacement with the frozen elephant trunk technique: 10-year follow-up single-centre experience. Eur J Cardiothorac Surg. 2013;44(5):949-57. doi:10.1093/ejcts/ezt229.

10. Verhoye JP, Anselmi A, Kaladji A, Flécher E, Lucas A, Heautot JF, et al. Mid-term results of elective repair of extensive thoracic aortic pathology by the Evita open plus hybrid endoprosthesis only. Eur J Cardiothorac Surg. 2014;45(5):812-7. doi:10.1093/ejcts/ezt477.

11. Mestres CA, Tsagakis K, Pacini D, Di Bartolomeo R, Grabenwöger M, Borger $\mathrm{M}$, et al. One-stage repair in complex multisegmental thoracic aneurysmal disease: results of a multicentre study. Eur J Cardiothorac Surg. 2013;44(5):e325-31. doi:10.1093/ejcts/ezt374.

12. Tsagakis K, Dohle D, Benedik J, Lieder H, Jakob H. Overall Essen's experience with the e-vita open hybrid stent graft system and evolution of the surgical technique. Ann Cardiothorac Surg. 2013;2(5):612-20. doi:10.3978/j.issn.2225-319X.2013.09.17.

13. Gorlitzer M, Weiss G, Moidl R, Folkmann S, Waldenberger F, Czerny M, et al. Repair of stent graft-induced retrograde type A aortic dissection using the e-vita open prosthesis. Eur J Cardiothorac Surg. 2012;42(3):566-70. doi:10.1093/ejcts/ezs041.

14. Di Eusanio M, Armaro A, Di Marco L, Pacini D, Savini C, Suarez SM, et al. Short- and midterm results after hybrid treatment of chronic aortic dissection with the frozen elephant trunk technique. Eur J Cardiothorac Surg. 2011;40(4):875-80. doi:10.1016/j.ejcts.2011.01.068.

15. Pacini D, Tsagakis K, Jakob H, Mestres CA, Armaro A, Weiss G, et al. The frozen elephant trunk for the treatment of chronic dissection of the thoracic aorta: a multicenter experience. Ann Thorac Surg. 2011;92(5):1663-70; discussion 1670. doi:10.1016/j.athoracsur.2011.06.027.

16. Weiss G, Tsagakis K, Jakob H, Di Bartolomeo R, Pacini D, Barberio G, et al. The frozen elephant trunk technique for the treatment of complicated type $B$ aortic dissection with involvement of the aortic arch: multicentre early experience. Eur J Cardiothorac Surg. 2015;47(1):106-14; discussion 114. doi:10.1093/ejcts/ezu067.

17. Hoffman A, Damberg ALM, Schälte G, Mahnken AH, Raweh A, Autschbach $R$. Thoracic stent graft sizing for frozen elephant trunk repair in acute type A dissection. JThorac Cardiovasc Surg. 2013;145(4):964-9. e1. doi:10.1016/j.jtcvs.2012.03.059.

18. Di Bartolomeo R, Di Marco L, Armaro A, Marsilli D, Leone A, Pilato E, et al. Treatment of complex disease of the thoracic aorta: the frozen elephant trunk technique with the e-vita open prosthesis. Eur J Cardiothorac Surg. 2009;35(4):671-5; discussion 675-6. doi:10.1016/j.ejcts.2008.12.010.

19. Tsagakis K, Pacini D, Di Bartolomeo R, Benedik J, Cerny S, Gorlitzer M, et al. Arch replacement and downstream stent grafting in complex aortic dissection: first results of an international registry. Eur J Cardiothorac Surg. 2011;39(1):87-93; discussion 93-4. doi:10.1016/j.ejcts.2010.03.070.

20. Di Bartolomeo R, Pacini D, Savini C, Pilato E, Martin-Suarez S, Di Marco L, et al. Complex thoracic aortic disease: single-stage procedure with the frozen elephant trunk technique. JThorac Cardiovasc Surg. 2010;140(6 Suppl):S81-5; discussion S86-91. doi:10.1016/j.jtcvs.2010.07.039.

21. Zipfel B, Buz S, Hammerschmidt R, Krabatsch T, Duesterhoeft V, Hetzer R. Early clinical experience with the e-vita thoracic stent-graft system: a single center study. J Cardiovasc Surg (Torino). 2008;49(4):417-28.

22. Leontyev S, Borger MA, Etz CD, Moz M, Seeburger J, Bakhtiary F, et al. Experience with the conventional and frozen elephant trunk techniques: a single-centre study. Eur J Cardiothorac Surg. 2013;44(6):1076-82; discussion 1083. doi:10.1093/ejcts/ezt252.

23. Verhoye JP, Belhaj Soulami R, Fouquet O, Ruggieri VG, Kaladji A, Tomasi J, et al. Elective frozen elephant trunk procedure using the e-vita open plus prosthesis in 94 patients: a multicentre French registry. Eur J Cardiothorac Surg. 2017;52(4):733-9. doi:10.1093/ejcts/ezx159.

24. Leontyev S, Misfeld M, Daviewala P, Borger MA, Etz CD, Belaev S, et al. 
Early- and medium-term results after aortic arch replacement with frozen elephant trunk techniques-a single center study. Ann Cardiothorac Surg. 2013;2(5):606-11. doi:10.3978/j.issn.2225-319X.2013.09.22.

25. Di Eusanio M, Pantaleo A, Murana G, Pellicciari G, Castrovinci S, Berretta $P$, et al. Frozen elephant trunk surgery-the Bologna's experience. Ann Cardiothorac Surg. 2013;2(5):597-605. doi:10.3978/j.issn.2225319X.2013.08.01.

26. Di Eusanio M, Borger M, Petridis FD, Leontyev S, Pantaleo A, Moz M, et al. Conventional versus frozen elephant trunk surgery for extensive disease of the thoracic aorta. J Cardiovasc Med (Hagerstown). 2014;15(11):803-9. doi:10.2459/JCM.0b013e328364559c.

27. Leontyev S, Tsagakis K, Pacini D, Di Bartolomeo R, Mohr FW, Weiss G, et al. Impact of clinical factors and surgical techniques on early outcome of patients treated with frozen elephant trunk technique by using EVITA open stent-graft: results of a multicentre study. Eur J Cardiothorac Surg. 2016;49(2):660-6. doi:10.1093/ejcts/ezv150.

28. Jakob H, Dohle D, Benedik J, Jánosi RA, Schlosser T, Wendt D, et al. Long-term experience with the e-vita open hybrid graft in complex thoracic aortic disease. Eur J Cardiothorac Surg. 2017;51(2):329-38. doi:10.1093/ejcts/ezw340.

29. Shrestha M, Kaufeld T, Beckmann E, Fleissner F, Umminger J, Abd Alhadi F, et al. Total aortic arch replacement with a novel 4-branched frozen elephant trunk prosthesis: single-center results of the first 100 patients. JThorac Cardiovasc Surg. 2016;152(1):148-59.e1. doi:10.1016/j. jtcvs.2016.02.077.

30. Shrestha M, Pichlmaier M, Martens A, Hagl C, Khaladj N, Haverich A. Total aortic arch replacement with a novel four-branched frozen elephant trunk graft: first-in-man results. Eur J Cardiothorac Surg. 2013;43(2):406-10. doi:10.1093/ejcts/ezs296.
31. Di Marco L, Pacini D, Leone A, Pantaleo A, Cefarelli M, Di Eusanio M, et al. The thoraflex hybrid frozen elephant trunk device: the Bologna experience. J Vasc Endovasc Surg. 2014;21(3):117-23.

32. Landau JH, Dubois LA, Power AH, Duncan A, Derose G, Chu MWA. Thoraflex hybrid endovascular frozen elephant trunk device for treatment of complex aortic arch disease. J Vasc Surg. 2017;66(3):e68.

33. Wong RH, Ho JY, Underwood MJ. Multimodality imaging assessment for thoraflex hybrid total arch replacement. Asian Cardiovasc Thorac Ann. 2016;24(5):496-501. doi:10.1177/0218492316643844.

34. Safi HJ, Miller CC 3rd, Estrera AL, Huynh TT, Rubenstein FS, Subramaniam MH, et al. Staged repair of extensive aortic aneurysms: morbidity and mortality in the elephant trunk technique. Circulation. 2001;104(24):2938-42. doi:10.1161/hc4901.100362.

35. Castrovinci S, Murana G, de Maat GE, Smith T, Schepens MAAM, Heijmen $\mathrm{RH}$, et al. The classic elephant trunk technique for staged thoracic and thoracoabdominal aortic repair: long-term results. JThorac Cardiovasc Surg. 2015;149(2):416-22. doi:10.1016/j.jtcvs.2014.09.078.

36. Lin HH, Liao SF, Wu CF, Li PC, Li ML. Outcome of frozen elephant trunk technique for acute type A aortic dissection: as systematic review and meta-analysis. Medicine (Baltimore). 2015;94(16):e694. doi:10.1097/ MD.0000000000000694.

37. Tian DH, Wan B, Di Eusanio M, Black D, Yan TD. A systematic review and meta-analysis on the safety and efficacy of the frozen elephant trunk technique in aortic arch surgery. Ann Cardiothorac Surg. 2013;2(5):58191. doi:10.3978/j.issn.2225-319X.2013.09.07.

38. Moulakakis KG, Mylonas SN, Markatis F, Kotsis T, Kakisis J, Liapis CD. A systematic review and meta-analysis of hybrid aortic arch replacement. Ann Cardiothorac Surg. 2013;2(3):247-60. doi:10.3978/j.issn.2225319X.2013.05.06. 